\title{
Mesonephric Duct
}

National Cancer Institute

\section{Source}

National Cancer Institute. Mesonephric Duct. NCI Thesaurus. Code C26469.

A duct in the embryo draining the mesonephric tubules. 